\title{
Hypertension and obstructive sleep apnea
}

This article was published in the following Dove Press journal:

Nature and Science of Sleep

9 May 2013

Number of times this article has been viewed

\author{
Craig L Phillips ${ }^{1-3}$ \\ Denise M O’Driscoll ${ }^{4,5}$ \\ 'Department of Respiratory and \\ Sleep Medicine, Royal North Shore \\ Hospital, Sydney, Australia; ${ }^{2}$ National \\ Health and Medical Research Council \\ Center for Integrated Research and \\ Understanding of Sleep, Woolcock \\ Institute of Medical Research, \\ University of Sydney, Sydney, Australia; \\ ${ }^{3}$ Discipline of Sleep Medicine, Sydney \\ Medical School, University of Sydney, \\ Sydney, Australia; ${ }^{4}$ Monash Lung \\ and Sleep, Monash Medical Centre, \\ Monash University, Melbourne, \\ Australia; ${ }^{5}$ Department of Medicine, \\ Southern Clinical School, Monash \\ University, Melbourne, Australia
}

\begin{abstract}
Obstructive sleep apnea (OSA) is increasingly being recognized as a major health burden with strong focus on the associated cardiovascular risk. Studies from the last two decades have provided strong evidence for a causal role of OSA in the development of systemic hypertension. The acute physiological changes that occur during apnea promote nocturnal hypertension and may lead to the development of sustained daytime hypertension via the pathways of sympathetic activation, inflammation, oxidative stress, and endothelial dysfunction. This review will focus on the acute hemodynamic disturbances and associated intermittent hypoxia that characterize OSA and the potential pathophysiological mechanisms responsible for the development of hypertension in OSA. In addition the epidemiology of OSA and hypertension, as well as the role of treatment of OSA, in improving blood pressure control will be examined.
\end{abstract}

Keywords: obstructive sleep apnea, hypertension, intermittent hypoxia, ambulatory blood pressure, sympathetic activation

\section{Introduction}

Obstructive sleep apnea (OSA) is characterized by recurrent periods of complete or partial collapse of the upper airway during sleep (apneas and hypopneas), causing sleep fragmentation and frequent awakenings which often result in excessive daytime sleepiness. In more severe forms of the disease, periods of obstructed breathing result in profound intermittent hypoxia (IH) with underlying bursts in sympathetic nerve activity (SNA) and dramatic increases in heart rate (HR) and blood pressure (BP). The severity of OSA is determined by the apnea hypopnea index $(\mathrm{AHI})^{1}$ which is a measure of the number of periods of obstructed breathing per hour of sleep. The prevalence of OSA (AHI $>5$ events/hour) with associated daytime sleepiness has been estimated at between $2 \%$ and $7 \%$ in diverse middle aged adult populations, ${ }^{2}$ whilst the prevalence of OSA (AHI $>1$ event/hour) in children is between $1 \%-3 \% .^{3}$ Adults with OSA are typically centrally obese, and although this obesity is strongly causally linked to the condition, there is an increased prevalence of cardiovascular morbidity and mortality amongst OSA sufferers above what would be expected from obesity alone. In addition to OSA, patients often present with one or more comorbidities including dyslipidemia, glucose intolerance, and hypertension. In the past two decades, research has focused on establishing whether OSA increases cardiovascular risk, either via the exacerbation of these risk factors or by other mechanisms. Amongst these, the strongest evidence that OSA lies on the causal pathway to cardiovascular disease is via the promotion of hypertension (Figure 1). It is therefore likely that the development of cardiovascular
Correspondence: Craig L Phillips Department of Respiratory and Sleep Medicine, Level 8, Acute Services Building, Royal North Shore Hospital, St Leonards, NSW 2065, Australia Tel +6I 294632936

Email craig.phillips@sydney.edu.au 


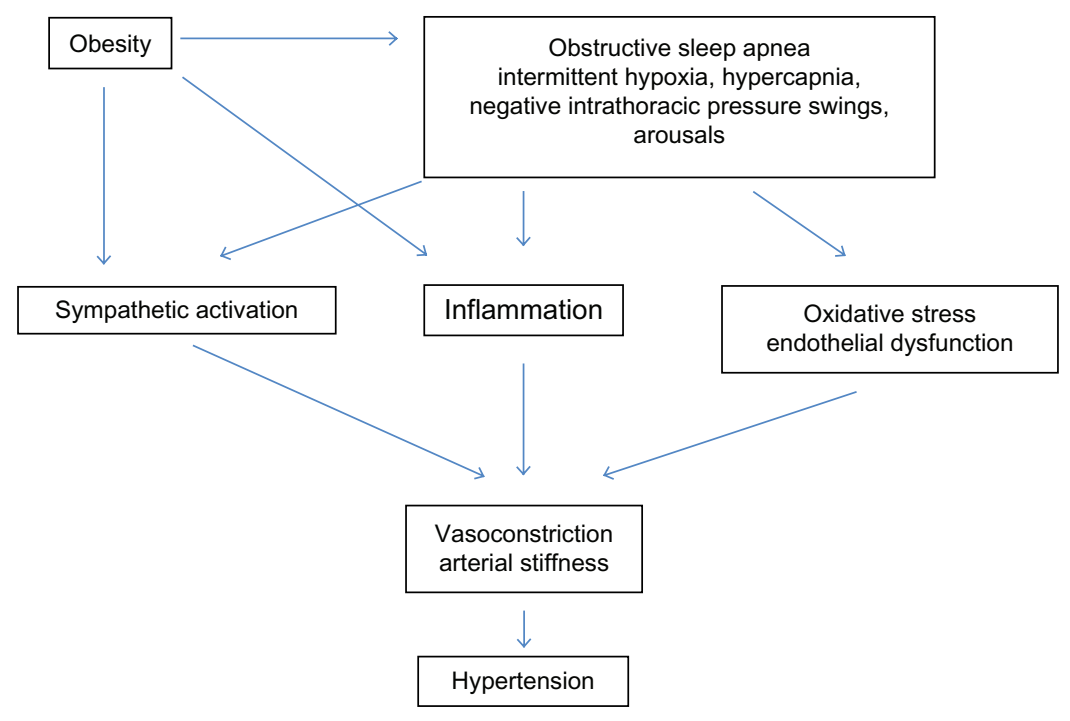

Figure I Schematic diagram showing the pathophysiological mechanisms linking obstructive sleep apnea with the development of hypertension.

complications, including coronary artery disease and stroke, in these patients is at least partially driven by the underlying OSA.

In this review we will present an overview of how the acute hemodynamic disturbances and associated $\mathrm{IH}$ that characterize OSA during sleep may promote not only nocturnal hypertension, but also sustained daytime hypertension. We will summarize the epidemiological evidence linking OSA to hypertension and the potential pathophysiological mechanisms responsible. We will also critically evaluate the role of OSA treatment in improving BP control. Finally, we will outline how future research may potentially increase our understanding of the OSAhypertension link and how management of both conditions may reduce risk of adverse outcomes.

\section{Normal blood pressure and cardiovascular risk}

In healthy individuals, sleep is associated with a $10 \%-15 \%$ reduction in systolic and diastolic BP compared to wakefulness. ${ }^{4}$ Referred to as "BP dipping", this reduction coincides with the sympathetic withdrawal and subsequent parasympathetic predominance that occurs when going from wake to non-rapid eye movement (NREM) sleep. Indeed all measures of cardiovascular activity show diurnal variations in activity with levels higher during the day and reducing during sleep, due to the interacting effects of the sleep-wake and circadian cycles. Compared with wakefulness, NREM sleep is associated with lower BP, HR, cardiac output, and systemic vascular resistance. Rapid eye movement (REM) sleep on the other hand is punctuated by transient surges in SNA, HR, and
BP. However, as REM constitutes only approximately $20 \%$ of total sleep, the net effect on cardiovascular measures is still a reduction from wake levels.

Sleep-related BP dipping is considered important for cardiovascular health, whilst absent or diminished nocturnal dipping of BP has been shown to be a strong independent predictor of cardiovascular risk. In the Ohasama study ${ }^{5}$ of 1464 individuals, it was shown that nighttime, as well as daytime BP measured by 24 hour ambulatory blood pressure monitoring (ABPM), were linearly related with stroke risk. In addition, in the Anglo-Scandinavian Cardiac Outcomes Trial, ${ }^{6}$ increased nighttime systolic BP (SBP) was associated with an increased risk of cardiovascular events. Other population studies have confirmed the cardiovascular benefit of the normal sleep-related decrease in BP.,

Importantly, it has also been shown that ABPM is superior to clinic measurement in predicting cardiovascular mortality. The Dublin Outcome Study ${ }^{9}$ measured both clinic and ABPM in 5292 individuals and demonstrated that nighttime BP was overall the best predictor of cardiovascular risk, with a $10 \mathrm{mmHg}$ increase in mean nighttime SBP being associated with a $21 \%$ increase in cardiovascular mortality. The measurement of nighttime BP may be particularly important in people who are taking antihypertensive medication because in these individuals, daytime SBP loses its predictive value for fatal and nonfatal cardiovascular events. In contrast, nighttime SBP predicts mortality and nonfatal events regardless of treatment status. ${ }^{10}$ In the context of this review, ABPM likely provides the best prognostic value in OSA patients because they typically have raised 
nocturnal BP and many are treated with antihypertensive medication.

\section{Hemodynamic effects of OSA}

The acute hemodynamic effects of OSA have been well described in the literature. The effects of upper airway occlusion and subsequent hypoxia, hypercapnia, large negative intrathoracic pressure swings, and arousal from sleep, all lead to acute increases in peripheral vasoconstriction, resulting in increased $\mathrm{BP}$.

During upper airway occlusion, both HR and BP initially decrease and then progressively increase. Peripheral SNA also increases, most likely caused by the synergistic influence of hypoxia and hypercapnia. Central hypercapnic chemoreceptor stimulation is a potent stimulus for ventilation and SNA. ${ }^{11,12}$ Hypoxic stimulation of peripheral chemoreceptors also increases ventilation and causes systemic vasoconstriction, with both acute and chronic increases in SNA. ${ }^{13}$ Combined hypercapnic and hypoxic stimulation produces a synergistic increase in SNA that is more than additive. ${ }^{12}$ Upon resumption of ventilation at airway reopening, and often coincident with arousal from sleep, there is a large surge in HR (tachycardia) ${ }^{14}$ superimposed upon hypoxia-induced peripheral vasoconstriction, resulting in a large increase in BP. Resumption of ventilation also marks the abrupt decline in SNA and this is most likely due to inhibition via stimulation of pulmonary afferents.

Cardiovascular analyses during and post obstructive events in adults have reported acute increases in BP and $\mathrm{HR}$ in excess of $20 \mathrm{mmHg}$ and 15 beats per minute (bpm), respectively. Mean BP following an obstructive apnea has been shown to increase by $32 \mathrm{mmHg}$ during NREM and $42 \mathrm{mmHg}$ during REM sleep. ${ }^{15}$ Similarly, two studies both reported BP surges $>20 \mathrm{mmHg} \cdot{ }^{16,17}$ Increases in HR of $15 \mathrm{bpm}$ overall have been reported, ${ }^{18}$ whilst increases of $18 \mathrm{bpm}$ in NREM and $30 \mathrm{bpm}$ in REM have also been reported. ${ }^{19}$ Whilst these reports in adults describe larger HR and BP responses in REM sleep as compared with NREM, these respiratory events are usually longer and associated with more profound oxygen desaturation. In contrast, although the magnitudes of cardiovascular changes are similar in children, the response is larger in NREM even when event duration and oxygen desaturation are controlled for. ${ }^{20}$ This sleep state difference is most likely due to the increased ventilatory response to hypoxia leading to a larger inspiratory effort upon resumption of breathing. The lack of an independent effect of sleep state in adults may be due to a reduction in ventilatory and cardiac chronotropic responses to hypoxia from childhood to adulthood. ${ }^{21}$
A further contributor to the hemodynamic changes with apnea is arousal from sleep which often coincides with apnea termination. The arousal state itself involves an increase in cardiac sympathetic activation and a withdrawal of parasympathetic activity. ${ }^{22}$ It is well documented in adults that even spontaneous arousal causes significant cardiovascular changes that are beyond functional requirements. Arousal has also been found to be a strong determinant of cardiovascular changes at the termination of obstructive events in adults ${ }^{23}$ and children, ${ }^{20}$ with the change in cardiovascular activity postevent being proportional to the duration of arousal. Thus, while cardiovascular activity increases upon resumption of ventilation, arousal also exerts a further influence on the magnitude of the perturbation.

\section{Mechanisms promoting hypertension in OSA Sympathetic activation}

The most noteworthy mechanism by which OSA may increase $\mathrm{BP}$ is through the acute and chronic increases in sympathetic activation associated with the condition. This effect is not limited to the acute apnea but manifests as sustained increases in sympathetic activation lasting through the day. Muscle SNA (MSNA) measured directly by microneurography has been shown to be elevated during sleep and remains elevated through the day compared with controls, long after the direct hemodynamic effects of apnea have subsided. ${ }^{24}$ Plasma catecholamine levels have also been shown to be elevated in awake patients with OSA compared with controls. ${ }^{25}$ Additionally, numerous studies have reported obesity independent elevations in both nocturnal ${ }^{26}$ and 24 hour urinary catecholamines ${ }^{27-30}$ in patients with OSA. ${ }^{31}$ It is this heightened sympathetic activity that has been postulated as a mechanism for systemic hypertension in OSA by peripheral vascular remodeling and increased vascular resistance. Elevations in sympathetic activity in OSA appear to be strongly linked to chemoreflex activation driven by IH. Hypoxic stimulation of the carotid body leads to a reflex increase sympathetic activity, ventilation, HR, and BP. Notably, chronic IH has been shown to lead to long-lasting elevations in sympathetic activity by long-term facilitation. ${ }^{32}$

Animal and human studies have explored the role of IH on sympathoactivation and subsequent BP elevation. Rats exposed to IH (8 hours/day over 35 days) showed a striking increase in mean BP of $13.7 \mathrm{mmHg}$ when compared with controls. ${ }^{33}$ Subsequent studies found that not only did the IH lead to a significant increase in BP in rats, but surgical denervation of peripheral chemoreceptors 
prevented the increase. ${ }^{34}$ Furthermore, adrenal demedullation and chemical denervation of the peripheral sympathetic nervous system also prevented the increase in BP. Human studies utilizing IH have been able to show increases in sympathetic activity and BP over a shorter time period. Mean BP increased by $4 \mathrm{mmHg}$ in ten males exposed to IH for 6 hours/day for 4 days. ${ }^{35}$ Similarly, in twelve healthy subjects, 2 weeks of IH exposure increased SBP and diastolic BP (DBP) (by $8 / 5 \mathrm{mmHg}$ ) and MSNA. ${ }^{36}$ The role of sleep arousals in the development of hypertension was examined in dogs by simulating obstructive apneas during sleep. ${ }^{37}$ When comparing repetitively induced apneas with arousal from sleep with auditory induced arousals without respiratory disturbance, nocturnal mean BP increased during both protocols, but only the apneas resulted in an increase in daytime BP $(\sim 16 \mathrm{mmHg})$. This study suggests that the association between OSA and hypertension is specific to the apnea-arousal cycle and cannot be explained by increased arousals alone.

In addition to the role of hypoxia, permanent dysregulation of the cardiovascular control system may lead to sympathetic overactivity. The arterial baroreceptors are mechanoreceptors mainly located in the carotid sinuses and aortic arch. They respond to changes in carotid or aortic stretch elicited by rises or falls in arterial pressure. The repetitive cardiovascular surges previously described may have an important role in the impairment of baroreflex control seen in OSA patients. ${ }^{38-40}$

Whilst IH increases chemoreflex function, data is emerging showing that it also decreases baroreflex function. This imbalance between the chemoreflex and baroreflex contributes to the sympathetic activation by IH and may be mediated by the generation of reactive oxygen species (see section on "Oxidative stress"). ${ }^{41}$

\section{Activation of the renin-angiotensin- aldosterone system}

Activation of the renin-angiotensin-aldosterone system (RAAS) is another potential mechanism for the development of hypertension in OSA. The RAAS is a complex hormone system that regulates BP. Briefly, angiotensin II is a potent vasoconstrictor which also stimulates the secretion of the hormone aldosterone which alters sodium handling, resulting in fluid retention which also increases BP. One study reported increased angiotensin II and aldosterone levels in 24 patients with OSA when compared to 18 control subjects, ${ }^{42}$ whilst a second study demonstrated that the increase in BP from IH is abolished by blockade of the angiotensin II receptors. ${ }^{43}$ This suggests a role for the RAAS in the pathophysiology of hypertension associated with IH in OSA; however, more studies are required.

\section{Inflammation}

The repetitive oxygen desaturation, and more importantly resaturation, that characterizes IH in OSA may also contribute to the development of inflammation. Systemic inflammation is strongly linked to the pathogenesis of atherosclerosis and hypertension; however, its role in OSA is confounded by the presence of obesity, a chronic inflammatory state. Circulating inflammatory markers such as tumor necrosis factor-alpha (TNF- $\alpha$ ), C-reactive protein (CRP), and interleukin-6 (IL6) have been reported to be elevated in OSA, although some studies have yielded conflicting results possibly due to the confounding effects of obesity. One study found elevated CRP and IL6 levels in OSA patients when compared with controls, however, the patients with OSA were more obese. ${ }^{44}$ Subsequent studies have shown increased levels of CRP in patients with OSA that were independent of body mass index (BMI). ${ }^{45-47}$ Conversely, two studies found that obesity per se, rather than OSA, is a better predictor of CRP. ${ }^{48,49}$ Furthermore, a large community study failed to detect an independent association between CRP and OSA after adjustment for BMI, ${ }^{50}$ suggesting that the OSA-CRP relationship may be primarily driven by obesity. However, the Icelandic Sleep Apnea Cohort $(n=454)^{51}$ recently found that OSA severity is an independent predictor of IL 6 and CRP levels but interacts with obesity such that this association is found only in obese OSA patients.

The evidence for increased levels of the pro-inflammatory cytokine TNF- $\alpha$, however, is far more convincing. Several case-control studies have demonstrated elevated circulating TNF- $\alpha$ in patients with OSA when compared to controls, independent of obesity. ${ }^{52,53}$ Importantly, the oxygen desaturation index has been shown to be independently associated with TNF- $\alpha$ levels in OSA, supporting the key role of $\mathrm{IH}$ as a mediator of the inflammatory response. ${ }^{54}$

\section{Oxidative stress}

IH in OSA may also contribute to the development of hypertension by increasing oxidative stress. Oxidative stress results in the production of reactive oxygen species and reduces circulating nitric oxide (NO), a key endothelial derived molecule that mediates control of vascular tone. Impaired NO release from endothelial cells leads to vasoconstriction and is regarded as an initiator and promoter of cardiovascular disease in patients with OSA. In this context, several studies have documented increased markers of oxidative stress 
in OSA patients when compared to controls, including superoxide levels in blood neutrophils ${ }^{55}$ and 8-isoprostane levels in blood and exhaled breath condensate. ${ }^{56,57}$ One study found that exhaled 8-isoprostane levels correlated positively with the AHI, ${ }^{56}$ whilst another study also found lower nitrate and nitrite levels (reflecting lower overall NO production) in the OSA group. ${ }^{57}$

\section{Endothelial dysfunction}

Endothelial dysfunction is thought to play a fundamental role in the development of atherosclerosis and hypertension, and often precedes cardiovascular disease. Several studies have reported endothelial dysfunction by impaired endotheliumdependent vasodilation in patients with OSA independent of obesity. ${ }^{58-60}$ This is likely mediated by a reduction in nitric oxide, ${ }^{61}$ possibly due to increased oxidative stress. Furthermore, there have been at least two randomized trials with continuous positive airway pressure (CPAP) demonstrating improved endothelial function with treatment of OSA. ${ }^{62,63}$

\section{Epidemiology of OSA and hypertension}

The increased prevalence of hypertension in OSA populations, and of OSA in hypertension populations, has been a driving force for establishing the direction of causality.

\section{Prevalence of OSA in hypertension}

In studies which have examined the prevalence of OSA amongst hypertensive populations, $20 \%-40 \%$ of individuals have been subsequently diagnosed with comorbid OSA ${ }^{64-66}$ with levels as high as $71 \%$ amongst drug resistant hypertensives. ${ }^{67}$

\section{Prevalence of hypertension in OSA}

There are also multiple epidemiological studies in both clinic and community dwelling populations examining the prevalence and incidence of hypertension in OSA. In most, hypertension is identified from a static measure of office BP exceeding 140/90 $\mathrm{mmHg}$ and/or the prescription of BP lowering medication. A vast majority are crosssectional studies, some of which include $>1500$ subjects. An advantage of these larger studies is their adequate power to explore confounding effects from traditional risk factors including obesity, gender, age, and smoking. In a study involving 2677 adults who were referred to a sleep clinic, after adjusting for age, BMI, and gender, the odds of hypertension increased by $1 \%$ for every unit (event/hour) increase in the
AHI, with the prevalence levels for hypertension being $22.8 \%, 36.5 \%, 46 \%$, and $53.6 \%$ in subjects with no, mild, moderate, and severe OSA, respectively. ${ }^{68}$ Similarly, in a study ${ }^{69}$ of 1741 community dwelling subjects with suspected OSA who subsequently underwent polysomnography, both mild and moderate to severe OSA was significantly associated with the presence of hypertension. The age and BMI adjusted odds ratio (OR) for hypertension in mild OSA was 2.29, whilst that for moderate or severe OSA was 6.85. Interestingly, when the analysis was stratified by age and gender, this association was predominantly present in younger $(<50$ years old $)$ males. ${ }^{6}$

There are also some large prospective studies that were initially designed to examine the prevalence of OSA in the community which have also examined the OSA-hypertension association. The most notable of these community based studies (which are less prone to the pitfalls of selection bias) are the Wisconsin Sleep Cohort Study (WSCS) and the Sleep Heart Health Study (SHHS). ${ }^{70,72}$ In the WSCS, the crosssectional analysis of 1060 participants aged 30-60 years revealed that BP increased linearly with increasing AHI independent of age, gender, and BMI. ${ }^{70}$ In addition, the BMI adjusted OR for having hypertension ( $\mathrm{SBP} \geq 140 \mathrm{mmHg}$, and/or DBP $\geq 90 \mathrm{mmHg}$, or use of BP medication) was 1.21, 1.75, and 3.07 for AHI cutoffs set at 5, 15, and 30 events/ hour, respectively. The increase in risk of hypertension in this community sample was $4 \%$ for every unit increase in AHI. An important add-on component to this study has been the inclusion of ABPM in 147 subjects. ${ }^{71}$ The data revealed that individuals with OSA had a $9 / 5 \mathrm{mmHg}$ and $9 / 4 \mathrm{mmHg}$ greater daytime and nighttime $\mathrm{BP}$, respectively, than a nonOSA group. Furthermore, after controlling for obesity, age, and gender, there was a dose-response relationship between OSA severity and hypertension with ORs ranging from 2 for milder OSA (AHI $=5$ events/hour $)$ to 5 for more severe OSA (AHI $=25$ events/hour).

In an older ( $>40$ years) and ethnically more diverse group from the SHHS involving 6132 subjects, the BMI, smoking, and alcohol intake adjusted OR for hypertension comparing severe OSA to no OSA was lower, but still significant, at $1.37 .^{72}$ Significant associations were still present in analyses stratified by gender, age, ethnicity, and BMI. Furthermore, in a subanalysis $^{72}$ of 3670 subjects not taking antihypertensive medication, AHI was positively associated with BP in a dose dependent manner. It is important, however, to highlight that the level of risk is somewhat weakened in older individuals to the point where a subsequent analysis revealed ${ }^{73}$ no association with hypertension for any AHI severity in subjects 
aged $>60$ years. In contrast, significant associations were present for all levels of OSA in subjects aged between 40-59 years. ${ }^{73}$ Although there are no clear reasons for the lack of association between OSA and hypertension in the elderly, survival bias or perhaps the age-related reduction in the cardiovascular response to arousal from sleep ${ }^{74}$ may play a role.

Although a meta-analysis of pediatric studies published before $2007^{75}$ found no evidence that OSA in childhood is associated with elevated BP, as BP elevation seen in association with childhood OSA rarely surpasses the 95th percentile, more recent large studies have shown an association. ABPM in 306 children from the general community showed, independent of obesity, increasing BP levels with increasing OSA severity, and children with moderate to severe disease (AHI $>5$ events/hour) were at significantly higher risk for nocturnal systolic (OR 3.9) and diastolic (OR 3.3) hypertension. ${ }^{76}$ A second ABPM study also reported higher nocturnal and diurnal BP in children with OSA ( $>5$ events/hour). ${ }^{77}$ In addition, in 140 children who had ABPM every 15 minutes, 24 hour BP and HR were significantly increased in children with OSA when compared with healthy controls. ${ }^{78}$ Similar findings occurred in a population sample of 700 elementary school children where there was a dose-response relationship between AHI and SBP after adjusting for multiple confounders including age, gender, and BMI. ${ }^{79}$ However, as only one quarter of the sample had OSA and most of these were mild in severity, the strength of the association is unclear. Interestingly, snoring was significantly associated with BP, independent of OSA. However, this finding is in contrast to a later study showing that parentally reported snoring was not independently associated with BP, carotid artery intima media thickness, or measures of arterial stiffness. ${ }^{80}$

\section{Incident hypertension in OSA}

Collectively, the cross-sectional studies strongly support an association between OSA and hypertension; however, the adjusted ORs for hypertension seem to vary considerably between studies. This variation may be due to differences in a number of factors between studies including baseline age and BMI, as well as ethnically homogenous versus diverse populations. As with all cross-sectional studies however, they are unable to demonstrate causality since the temporal development of OSA and hypertension in relation to one another are unknown. To try and answer this question, there have been four longitudinal cohort studies which have allowed examination of incident and/or persistence of hypertension at follow-up. In the WSCS, 709 participants were followed up to 4 years after baseline. ${ }^{81}$ After adjusting for baseline hypertension status, age, gender, alcohol, and smoking, relative to an AHI of 0 events/hour at baseline, the ORs for the presence of hypertension at follow-up were 1.42 with an AHI of 0.1-4.9 events/hour, 2.03 with an AHI of 5.0-14.9 events/hour, and 2.89 with an AHI of $>15.0$ events/hour. Similar findings occurred in the more recent Zaragoza Sleep Cohort Study, a prospective study of 1889 subjects without hypertension who were referred for polysomnographic investigation of OSA. ${ }^{82}$ The investigators assessed the occurrence of new onset hypertension in subjects without OSA and in subjects who remained untreated for their OSA. Compared to controls, all untreated groups had significantly increased hazard ratios for developing new onset hypertension. Of particular importance, there has also been a longitudinal analysis ${ }^{83}$ over 7.2 years of the WSCS subsample that underwent ABPM $(\mathrm{n}=328)$. The odds for incident systolic nondipping were 3.1 and 4.4 for mild (AHI $=5-15$ events/hour) and moderate to severe (AHI $\geq 15$ events/hour) OSA, respectively. ${ }^{83}$

In contrast, incident hypertension in OSA is not supported by either of the two other community cohort studies. ${ }^{84,85}$ The SHHS followed up 2470 subjects for 5 years who were free of hypertension at baseline and found that the risk for incident hypertension significantly increased with increasing baseline AHI ${ }^{84}$ However, in the models which adjusted for baseline BMI, the risk was markedly attenuated and became nonsignificant. In addition, the Vitoria Cohort Study ${ }^{85}$ in Spain assessed hypertensive status after 7.5 years in 1180 subjects aged 30-70 years who were free from hypertension at baseline. At baseline, all participants underwent a home-based respiratory study and then approximately half also underwent polysomnography to validate the home study. The age, gender, BMI, alcohol, caffeine, and tobacco consumption adjusted OR for incident hypertension according to respiratory disturbance index was not statistically significant leading the authors to conclude that a causal relationship between OSA and hypertension in the middle aged general population may not exist. ${ }^{85}$ Finally, we are not aware of any longitudinal cohort studies in children where objectively defined measures of OSA at baseline predict incident hypertension.

Overall, cross-sectional studies show clear associations between OSA severity and hypertension in adults but the data in children is less clear. However, not all longitudinal studies in adults support a causal relationship. Further cohort studies which begin at ages where OSA and hypertension are both 
absent but continue during the evolution of either condition are needed to more clearly discern the natural history of the two disease processes.

\section{Treatment of OSA and treatment of hypertension in OSA patients Effects of OSA treatment on blood pressure}

There are multiple observational studies suggesting that treatment of OSA with CPAP lowers BP. However, it has only been in the past decade that these effects have been more rigorously tested using randomized control trial (RCT) designs. To date, there have been at least 19 RCTs with over 1600 patients examining the effects of OSA treatment on BP. ${ }^{86}$ In these studies, the control involved sham (subtherapeutic) devices, placebo pills, or no treatment. Most, but not all, studies demonstrate a BP lowering effect; however, the responses are widely variable. This variability in response has been attributed to the heterogeneity of enrolled patients in relation to age, OSA severity, sleepiness, and hypertensive status (including coexisting pharmacological antihypertensive treatment), as well as variability in treatment compliance and duration. In general, for studies with CPAP, the greatest antihypertensive effects occurred when nightly compliance was $>5$ hours and patients had preexisting hypertension and severe OSA. The effects are particularly marked when trials measured 24 hour ABPM where CPAP treatment was associated with reductions in both systolic and diastolic pressures during wakefulness and sleep. ${ }^{86}$

In an attempt to more clearly define the response to treatment, three meta-analyses were conducted, all in 2007. ${ }^{87-89}$ Two analyses, ${ }^{87,88}$ suggested an overall small $(1.5-2.5 \mathrm{mmHg})$ reduction in systolic and diastolic BP, whilst the third analysis suggested no significant reduction in any pressures. ${ }^{89}$ Since these analyses, there have been a number of additional trials ${ }^{90-92}$ including two large studies from Spain targeting predominantly severe OSA patients, and a third study from India targeting OSA patients with a high prevalence of metabolic syndrome. The first Spanish study, using ABPM, targeted hypertensive patients who had predominantly severe OSA and found a small ( $<3 \mathrm{mmHg}$ ) BP reduction after 3 months. ${ }^{91}$ The second Spanish study, using office BP targeted nonsleepy patients, also with predominantly severe OSA, found a reduction in diastolic BP that only became evident after 12 months of treatment. ${ }^{92}$ The Indian study was a 3-month CPAP-Sham CPAP crossover study where BP during CPAP was 3.9/2.5 mmHg lower than on Sham CPAP. ${ }^{90}$
The overall average change in BP across all trials can be summarized as of a modest magnitude. Nevertheless, even these modest changes are likely to significantly reduce the occurrence of cardiovascular events. ${ }^{93}$

More recently, there have been two studies that are the first to explore the association between CPAP therapy for OSA and incident hypertension. ${ }^{82,94}$ The (previously mentioned) Zaragoza Sleep Cohort Study is a prospective observational study which found significantly lower risk of incident hypertension after 12.2 years of follow-up amongst compliant CPAP users compared to nonusers. ${ }^{82}$ However, it is important to consider that the observational nature of this study makes it prone to selection bias, including the possibility that CPAP users were healthier and more compliant with medication compared to the nonCPAP group. In contrast, the second study, also from Spain, followed 723 nonsleepy OSA patients randomized to CPAP or no intervention for 4 years. ${ }^{94}$ The authors found a nonsignificant reduction in incident hypertension in the CPAP group when compared to the nonCPAP group. However, in a post hoc analysis, compliant CPAP use ( $>4$ hours/night) was associated with reduction in incident hypertension. This highlights the importance of good treatment compliance in modulating the antihypertensive effect.

\section{Pharmacological treatments effects on blood pressure}

There are surprisingly few studies examining the impact of BP lowering medication in OSA patients with hypertension. Only one small RCT with 20 patients examined the five major antihypertensive drug classes. ${ }^{95}$ The study used a balanced incomplete block randomization design with each patient receiving two drugs, each for 6 weeks, in a randomized order with a 3 week washout. This resulted in each agent being tested in eight patients. This study found similar reductions in daytime BP $(\sim 10 \mathrm{mmHg})$ across all classes. Although the small sample size could have limited the ability to detect between class differences in BP lowering, beta-blocker and diuretic therapy did reduce nighttime BP more than the other agents. Unfortunately, this poses a problem because both beta-blockers and diuretics have been associated with increased risk of new onset diabetes, ${ }^{96,97}$ with betablocker therapy being associated with a greater incidence of cardiovascular morbidity and mortality. ${ }^{98}$ There is, however, some encouraging new data suggesting that antihypertensive treatment with a mineralocorticoid receptor antagonist in OSA patients with resistant hypertension substantially improves both BP and OSA severity. ${ }^{99}$ The latter effect may 
be mediated through a reduction in upper airway edema, and if confirmed in larger randomized trials, these agents may provide a promising treatment for hypertension in this group.

\section{Summary and future directions}

There is an abundance of evidence implicating OSA as an important secondary cause of hypertension. The mechanisms likely involve sustained, increased sympathetic activation associated with intermittent hypoxia. In the long-term, BP elevation, together with other less well understood processes, is likely to explain the increase in cardiovascular related morbidity, events, and death that are seen in this group. While there is good evidence that effective treatment of more severe OSA in patients with hypertension improves BP, future research should be directed at more clearly identifying factors that determine individual antihypertensive responses with OSA treatment. In addition, further studies are required to explore the effect of long-term treatment of OSA on BP. Whilst OSA-induced hypertension could lead to further vascular remodeling or structural cardiac changes, it also remains to be demonstrated whether BP reduction decreases OSA-mediated cardiovascular risk. Given the consistent relationship between hypertension and risk of cardiovascular disease (such as stroke and heart failure), it is important to adopt strategies which have a maximal BP lowering effect. In populations with OSA and hypertension, the best strategy likely involves combining OSA treatment with antihypertensive medication. This combination is likely to be more effective in lowering both nocturnal and daytime BP than either treatment alone. The subsequent reduction in cardiovascular risk may be substantial.

\section{Disclosure}

The authors report no conflicts of interest in this work.

\section{References}

1. Epstein LJ, Kristo D, Strollo PJ Jr et al. Adult Obstructive Sleep Apnea Task Force of the American Academy of Sleep Medicine. Clinical guideline for the evaluation, management and long-term care of obstructive sleep apnea in adults. J Clin Sleep Med. 2009;15:5(3):263-276.

2. Punjabi NM, Caffo BS, Goodwin JL, et al. Sleep-disordered breathing and mortality: a prospective cohort study. PLoS Med. 2009;6(8):e1000132.

3. Ebert CS, Drake AF. The impact of sleep-disordered breathing on cognition and behavior in children: a review and meta-synthesis of the literature. Otolaryngol Head Neck Surg. 2004;131(6):814-826.

4. Trinder J, Kleiman J, Carrington M, et al. Autonomic activity during human sleep as a function of time and sleep stage. $J$ Sleep Res. 2001; 10(4):253-264.

5. Ohkubo T, Hozawa A, Nagai K, et al. Prediction of stroke by ambulatory blood pressure monitoring versus screening blood pressure measurements in a general population: the Ohasama study. J Hypertens. 2000; 18(7):847-854.
6. Dolan E, Stanton AV, Thom S, et al. Ambulatory blood pressure monitoring predicts cardiovascular events in treated hypertensive patients - an Anglo-Scandinavian cardiac outcomes trial substudy. J Hypertens. 2009;27(4):876-885.

7. Kario K, Pickering TG, Matsuo T, Hoshide S, Schwartz JE, Shimada K. Stroke prognosis and abnormal nocturnal blood pressure falls in older hypertensives. Hypertension. 2001;38(4):852-857.

8. Ben-Dov IZ, Kark JD, Ben-Ishay D, Mekler J, Ben-Arie L, Bursztyn M. Predictors of all-cause mortality in clinical ambulatory monitoring: unique aspects of blood pressure during sleep. Hypertension. 2007;49(6):1235-1241.

9. Dolan E, Stanton A, Thijs L, et al. Superiority of ambulatory over clinic blood pressure measurement in predicting mortality: the Dublin outcome study. Hypertension. 2005;46(1):156-161.

10. Boggia J, LiY, Thijs L, et al. International Database on Ambulatory blood pressure monitoring in relation to Cardiovascular Outcomes (IDACO) Investigators. Prognostic accuracy of day versus night ambulatory blood pressure: a cohort study. Lancet. 2007;370(9594):1219-1229.

11. Berthon-Jones M, Sullivan CE. Ventilation and arousal responses to hypercapnia in normal sleeping humans. J Appl Physiol. 1984; 57(1):59-67.

12. Somers VK, Mark AL, Zavala DC, Abboud FM. Contrasting effects of hypoxia and hypercapnia on ventilation and sympathetic activity in humans. J Appl Physiol. 1989;67(5):2101-2106.

13. Leuenberger U, Jacob E, Sweer L, Waravdekar N, Zwillich C, Sinoway L. Surges of muscle sympathetic nerve activity during obstructive apnea are linked to hypoxemia. J Appl Physiol. 1995;79(2):581-588.

14. Garpestad E, Katayama H, Parker JA, et al. Stroke volume and cardiac output decrease at termination of obstructive apneas. J Appl Physiol. 1992;73(5):1743-1748.

15. Okabe S, Hida W, Kikuchi Y, et al. Role of hypoxia on increased blood pressure in patients with obstructive sleep apnoea. Thorax. 1995; 50(1):28-34.

16. Ali NJ, Davies RJ, Fleetham JA, Stradling JR. The acute effects of continuous positive airway pressure and oxygen administration on blood pressure during obstructive sleep apnea. Chest. 1992;101(6):1526-1532.

17. Davies RJ, Crosby J, Vardi-Visy K, Clarke M, Stradling JR. Non-invasive beat to beat arterial blood pressure during non-REM sleep in obstructive sleep apnoea and snoring. Thorax. 1994;49(4):335-339.

18. Jelic S, Bartels MN, Mateika JH, Ngai P, DeMeersman RE, Basner RC. Arterial stiffness increases during obstructive sleep apneas. Sleep. 2002; 25(8):850-855.

19. Stoohs R, Guilleminault C. Cardiovascular changes associated with obstructive sleep apnea syndrome. J Appl Physiol. 1992;72(2): 583-589.

20. O'Driscoll DM, Foster AM, Ng ML, et al. Acute cardiovascular changes with obstructive events in children with sleep disordered breathing. Sleep. 2009;32(10):1265-1271.

21. Marcus CL, Glomb WB, Basinski DJ, Davidson SL, Keens TG. Developmental pattern of hypercapnic and hypoxic ventilatory responses from childhood to adulthood. J Appl Physiol. 1994;76(1):314-320.

22. Horner RL, Brooks D, Kozar LF, Tse S, Phillipson EA. Immediate effects of arousal from sleep on cardiac autonomic outflow in the absence of breathing in dogs. J Appl Physiol. 1995;79(1):151-162.

23. Yoon IY, Jeong DU. Degree of arousal is most correlated with blood pressure reactivity during sleep in obstructive sleep apnea. $J$ Korean Med Sci. 2001;16(6):707-711.

24. Somers VK, Dyken ME, Clary MP, Abboud FM. Sympathetic neural mechanisms in obstructive sleep apnea. J Clin Invest. 1995; 96(4):1897-1904.

25. Carlson JT, Hedner J, Elam M, Ejnell H, Sellgren J, Wallin BG. Augmented resting sympathetic activity in awake patients with obstructive sleep apnea. Chest. 1993;103(6):1763-1768.

26. O'Driscoll DM, Horne RS, Davey MJ, et al. Increased sympathetic activity in children with obstructive sleep apnea: cardiovascular implications. Sleep Med. 2011;12(5):483-488. 
27. Fletcher EC, Miller J, Schaaf JW, Fletcher JG. Urinary catecholamines before and after tracheostomy in patients with obstructive sleep apnea and hypertension. Sleep. 1987;10(1):35-44.

28. Garcia-Rio F, Racionero MA, Pino JM, et al. Sleep apnea and hypertension. Chest. 2000;117(5):1417-1425.

29. Marrone O, Riccobono L, Salvaggio A, Mirabella A, Bonanno A, Bonsignore MR. Catecholamines and blood pressure in obstructive sleep apnea syndrome. Chest. 1993;103(3):722-727.

30. Solin P, Kaye DM, Little PJ, Bergin P, Richardson M, Naughton MT. Impact of sleep apnea on sympathetic nervous system activity in heart failure. Chest. 2003;123(4):1119-1126.

31. Lam JC, Yan CS, Lai AY, et al. Determinants of daytime blood pressure in relation to obstructive sleep apnea in men. Lung. 2009; 187(5):291-298.

32. Babcock MA, Badr MS. Long-term facilitation of ventilation in humans during NREM sleep. Sleep. 1998;21(7):709-716.

33. Fletcher EC, Lesske J, Qian W, Miller CC 3rd, Unger T. Repetitive, episodic hypoxia causes diurnal elevation of blood pressure in rats. Hypertension. 1992;19(6 Pt 1):555-561.

34. Lesske J, Fletcher EC, Bao G, Unger T. Hypertension caused by chronic intermittent hypoxia - influence of chemoreceptors and sympathetic nervous system. J Hypertens. 1997;15(12 Pt 2):1593-1603.

35. Foster GE, Brugniaux JV, Pialoux V, et al. Cardiovascular and cerebrovascular responses to acute hypoxia following exposure to intermittent hypoxia in healthy humans. J Physiol. 2009;587(Pt 13): 3287-3299.

36. Tamisier R, Pepin JL, Remy J, et al. 14 nights of intermittent hypoxia elevate daytime blood pressure and sympathetic activity in healthy humans. Eur Respir J. 2011;37(1):119-128.

37. Brooks D, Horner RL, Kozar LF, Render-Teixeira CL, Phillipson EA Obstructive sleep apnea as a cause of systemic hypertension. Evidence from a canine model. J Clin Invest. 1997;99(1):106-109.

38. Parati G, Di Rienzo M, Bonsignore MR, et al. Autonomic cardiac regulation in obstructive sleep apnea syndrome: evidence from spontaneous baroreflex analysis during sleep. J Hypertens. 1997; 15(12 Pt 2):1621-1626.

39. Bonsignore MR, Parati G, Insalaco G, et al. Continuous positive airway pressure treatment improves baroreflex control of heart rate during sleep in severe obstructive sleep apnea syndrome. Am J Respir Crit Care Med 2002;166(3):279-286.

40. Lombardi C, Parati G, Cortelli P, et al. Daytime sleepiness and neural cardiac modulation in sleep-related breathing disorders. J Sleep Res. 2008;17(3):263-270.

41. Prabhakar NR, Kumar GK, Peng YJ. Sympatho-adrenal activation by chronic intermittent hypoxia. J Appl Physiol. 2012;113(8): 1304-1310.

42. Moller DS, Lind P, Strunge B, Pedersen EB. Abnormal vasoactive hormones and 24-hour blood pressure in obstructive sleep apnea. Am J Hypertens. 2003;16(4):274-280.

43. Foster GE, Hanly PJ, Ahmed SB, Beaudin AE, Pialoux V, Poulin MJ. Intermittent hypoxia increases arterial blood pressure in humans through a Renin-Angiotensin system-dependent mechanism. Hypertension. 2010;56(3):369-377.

44. Yokoe T, Minoguchi K, Matsuo H, et al. Elevated levels of C-reactive protein and interleukin-6 in patients with obstructive sleep apnea syndrome are decreased by nasal continuous positive airway pressure. Circulation. 2003;107(8):1129-1134.

45. Hayashi M, Fujimoto K, Urushibata K, Takamizawa A, Kinoshita O, Kubo K. Hypoxia-sensitive molecules may modulate the development of atherosclerosis in sleep apnoea syndrome. Respirology. 2006; 11(1):24-31.

46. Can M, Acikgoz S, Mungan G, et al. Serum cardiovascular risk factors in obstructive sleep apnea. Chest. 2006;129(2):233-237.

47. Kokturk O, Ciftci TU, Mollarecep E, Ciftci B. Elevated C-reactive protein levels and increased cardiovascular risk in patients with obstructive sleep apnea syndrome. Int Heart J. 2005;46(5):801-809.
48. Guilleminault C, Kirisoglu C, Ohayon MM. C-reactive protein and sleep-disordered breathing. Sleep. 2004;27(8):1507-1511.

49. Ryan S, Nolan GM, Hannigan E, Cunningham S, Taylor C, McNicholas WT. Cardiovascular risk markers in obstructive sleep apnoea syndrome and correlation with obesity. Thorax. 2007;62(6): 509-514.

50. Taheri S, Austin D, Lin L, Nieto FJ, Young T, Mignot E. Correlates of serum C-reactive protein (CRP) - no association with sleep duration or sleep disordered breathing. Sleep. 2007;30(8):991-996.

51. Arnardottir ES, Maislin G, Schwab RJ, et al. The interaction of obstructive sleep apnea and obesity on the inflammatory markers C-reactive protein and interleukin-6: the Icelandic Sleep Apnea Cohort. Sleep. 2012;35(7):921-932.

52. Ciftci TU, Kokturk O, Bukan N, Bilgihan A. The relationship between serum cytokine levels with obesity and obstructive sleep apnea syndrome. Cytokine. 2004;28(2):87-91.

53. Minoguchi K, Tazaki T, Yokoe T, et al. Elevated production of tumor necrosis factor-alpha by monocytes in patients with obstructive sleep apnea syndrome. Chest. 2004;126(5):1473-1479.

54. Ryan S, Taylor CT, McNicholas WT. Predictors of elevated nuclear factor-kappaB-dependent genes in obstructive sleep apnea syndrome. Am J Respir Crit Care Med. 2006;174(7):824-830.

55. Schulz R, Mahmoudi S, Hattar K, et al. Enhanced release of superoxide from polymorphonuclear neutrophils in obstructive sleep apnea. Impact of continuous positive airway pressure therapy. Am J Respir Crit Care Med. 2000;162(2 Pt 1):566-570.

56. Carpagnano GE, Kharitonov SA, Resta O, Foschino-Barbaro MP, Gramiccioni E, Barnes PJ. 8-Isoprostane, a marker of oxidative stress, is increased in exhaled breath condensate of patients with obstructive sleep apnea after night and is reduced by continuous positive airway pressure therapy. Chest. 2003;124(4):1386-1392.

57. Alonso-Fernandez A, Garcia-Rio F, Arias MA, et al. Effects of CPAP on oxidative stress and nitrate efficiency in sleep apnoea: a randomised trial. Thorax. 2009;64(7):581-586.

58. Kato M, Roberts-Thomson P, Phillips BG, et al. Impairment of endothelium-dependent vasodilation of resistance vessels in patients with obstructive sleep apnea. Circulation. 2000;102(21):2607-2610.

59. Namtvedt SK, Hisdal J, Randby A, et al. Impaired endothelial function in persons with obstructive sleep apnoea: impact of obesity. Heart. 2012;99(1):30-34.

60. Kohler M, Craig S, Nicoll D, Leeson P, Davies RJ, Stradling JR. Endothelial function and arterial stiffness in minimally symptomatic obstructive sleep apnea. Am J Respir Crit Care Med. 2008;178(9):984-988.

61. Ip MS, Lam B, Chan LY, et al. Circulating nitric oxide is suppressed in obstructive sleep apnea and is reversed by nasal continuous positive airway pressure. Am J Respir Crit Care Med. 2000;162(6):2166-2171.

62. Ip MS, Tse HF, Lam B, Tsang KW, Lam WK. Endothelial function in obstructive sleep apnea and response to treatment. Am J Respir Crit Care Med. 2004;169(3):348-353.

63. Cross MD, Mills NL, Al-Abri M, et al. Continuous positive airway pressure improves vascular function in obstructive sleep apnoea/hypopnoea syndrome: a randomised controlled trial. Thorax. 2008;63(7):578-583.

64. Fletcher EC, DeBehnke RD, Lovoi MS, Gorin AB. Undiagnosed sleep apnea in patients with essential hypertension. Ann Intern Med. 1985; 103(2):190-195.

65. Lavie P, Ben-Yosef R, Rubin AE. Prevalence of sleep apnea syndrome among patients with essential hypertension. Am Heart J. 1984; 108(2):373-376.

66. Worsnop CJ, Naughton MT, Barter CE, Morgan TO, Anderson AI, Pierce RJ. The prevalence of obstructive sleep apnea in hypertensives. Am J Respir Crit Care Med. 1998;157(1):111-115.

67. Goncalves SC, Martinez D, Gus M, et al. Obstructive sleep apnea and resistant hypertension: a case-control study. Chest. 2007; 132(6):1858-1862.

68. Lavie P, Herer P, Hoffstein V. Obstructive sleep apnoea syndrome as a risk factor for hypertension: population study. BMJ. 2000; 320(7233):479-482. 
69. Bixler EO, Vgontzas AN, Lin HM, et al. Association of hypertension and sleep-disordered breathing. Arch Intern Med. 2000;160(15): 2289-2295.

70. Young T, Peppard P, Palta M, et al. Population-based study of sleepdisordered breathing as a risk factor for hypertension. Arch Intern Med. 1997;157(15):1746-1752.

71. Hla KM, Young TB, Bidwell T, Palta M, Skatrud JB, Dempsey J. Sleep apnea and hypertension. A population-based study. Ann Intern Med. 1994;120(5):382-388.

72. Nieto FJ, Young TB, Lind BK, et al. Association of sleep-disordered breathing, sleep apnea, and hypertension in a large community-based study. Sleep Heart Health Study. JAMA. 2000;283(14):1829-1836.

73. Haas DC, Foster GL, Nieto FJ, et al. Age-dependent associations between sleep-disordered breathing and hypertension: importance of discriminating between systolic/diastolic hypertension and isolated systolic hypertension in the Sleep Heart Health Study. Circulation. 2005;111(5):614-621.

74. Goff EA, O'Driscoll DM, Simonds AK, Trinder J, Morrell MJ. The cardiovascular response to arousal from sleep decreases with age in healthy adults. Sleep. 2008;31(7):1009-1017.

75. Zintzaras E, Kaditis AG. Sleep-disordered breathing and blood pressure in children: a meta-analysis. Arch Pediatr Adolesc Med. 2007; 161(2):172-178.

76. Li AM, Au CT, Sung RY, et al. Ambulatory blood pressure in children with obstructive sleep apnoea: a community based study. Thorax. 2008; 63(9):803-809.

77. Leung LC, Ng DK, Lau MW, et al. Twenty-four-hour ambulatory BP in snoring children with obstructive sleep apnea syndrome. Chest. 2006; 130(4):1009-1017.

78. Amin R, Somers VK, McConnell K, et al. Activity-adjusted 24-hour ambulatory blood pressure and cardiac remodeling in children with sleep disordered breathing. Hypertension. 2008;51(1):84-91.

79. Bixler EO, Vgontzas AN, Lin HM, et al. Blood pressure associated with sleep-disordered breathing in a population sample of children. Hypertension. 2008;52(5):841-846.

80. Marshall NS, Ayer JG, Toelle BG, et al. Snoring is not associated with adverse effects on blood pressure, arterial structure or function in 8-year-old children: the Childhood Asthma Prevention Study (CAPS). J Paediatr Child Health. 2011;47(8):518-523.

81. Peppard PE, Young T, Palta M, Skatrud J. Prospective study of the association between sleep-disordered breathing and hypertension. $N$ Engl J Med. 2000;342(19):1378-1384.

82. Marin JM, Agusti A, Villar I, et al. Association between treated and untreated obstructive sleep apnea and risk of hypertension. JAMA. 2012; 307(20):2169-2176.

83. Hla KM, Young T, Finn L, Peppard PE, Szklo-Coxe M, Stubbs M. Longitudinal association of sleep-disordered breathing and nondipping of nocturnal blood pressure in the Wisconsin Sleep Cohort Study. Sleep. 2008;31(6):795-800.

84. O'Connor GT, Caffo B, Newman AB, et al. Prospective study of sleepdisordered breathing and hypertension: the Sleep Heart Health Study. Am J Respir Crit Care Med. 2009;179(12):1159-1164.

85. Cano-Pumarega I, Duran-Cantolla J, Aizpuru F, et al. Obstructive sleep apnea and systemic hypertension: longitudinal study in the general population: the Vitoria Sleep Cohort. Am J Respir Crit Care Med. 2011;184(11):1299-1304.

Nature and Science of Sleep

\section{Publish your work in this journal}

Nature and Science of Sleep is an international, peer-reviewed, open access journal covering all aspects of sleep science and sleep medicine, including the neurophysiology and functions of sleep, the genetics of sleep, sleep and society, biological rhythms, dreaming, sleep disorders and therapy, and strategies to optimize healthy sleep. The journal welcomes
86. Parati G, Lombardi C, Hedner J, et al; European Respiratory Society, EU COST ACTION B26 members. Position paper on the management of patients with obstructive sleep apnea and hypertension: joint recommendations by the European Society of Hypertension, by the European Respiratory Society and by the members of European COST (COoperation in Scientific and Technological research) ACTION B26 on obstructive sleep apnea. J Hypertens. 2012;30(4):633-646.

87. Bazzano LA, Khan Z, Reynolds K, He J. Effect of nocturnal nasal continuous positive airway pressure on blood pressure in obstructive sleep apnea. Hypertension. 2007;50(2):417-423.

88. Haentjens P, Van Meerhaeghe A, Moscariello A, et al. The impact of continuous positive airway pressure on blood pressure in patients with obstructive sleep apnea syndrome: evidence from a metaanalysis of placebo-controlled randomized trials. Arch Intern Med. 2007;167(8):757-764.

89. Alajmi M, Mulgrew AT, Fox J, et al. Impact of continuous positive airway pressure therapy on blood pressure in patients with obstructive sleep apnea hypopnea: a meta-analysis of randomized controlled trials. Lung. 2007;185(2):67-72.

90. Sharma SK, Agrawal S, Damodaran D, et al. CPAP for the metabolic syndrome in patients with obstructive sleep apnea. $N$ Engl J Med. 2011;365(24):2277-2286.

91. Duran-Cantolla J, Aizpuru F, Montserrat JM, et al; Spanish Sleep and Breathing Group. Continuous positive airway pressure as treatment for systemic hypertension in people with obstructive sleep apnoea: randomised controlled trial. BMJ. 2010;341:c5991.

92. Barbe F, Duran-Cantolla J, Capote F, et al; Spanish Sleep and Breathing Group. Long-term effect of continuous positive airway pressure in hypertensive patients with sleep apnea. Am J Respir Crit Care Med. 2010;181(7):718-726.

93. Turnbull F. Effects of different blood-pressure-lowering regimens on major cardiovascular events: results of prospectively-designed overviews of randomised trials. Lancet. 2003;362(9395):1527-1535.

94. Barbe F, Duran-Cantolla J, Sanchez-de-la-Torre M, et al; Spanish Sleep and Breathing Network. Effect of continuous positive airway pressure on the incidence of hypertension and cardiovascular events in nonsleepy patients with obstructive sleep apnea: a randomized controlled trial. JAMA. 2012;307(20):2161-2168.

95. Kraiczi H, Hedner J, Peker Y, Grote L. Comparison of atenolol, amlodipine, enalapril, hydrochlorothiazide, and losartan for antihypertensive treatment in patients with obstructive sleep apnea. Am J Respir Crit Care Med. 2000;161(5):1423-1428.

96. Zillich AJ, Garg J, Basu S, Bakris GL, Carter BL. Thiazide diuretics, potassium, and the development of diabetes: a quantitative review. Hypertension. 2006;48(2):219-224.

97. Bangalore S, Parkar S, Grossman E, Messerli FH. A meta-analysis of 94,492 patients with hypertension treated with beta blockers to determine the risk of new-onset diabetes mellitus. Am J Cardiol. 2007;100(8):1254-1262.

98. Lindholm LH, Carlberg B, Samuelsson O. Should $\beta$ blockers remain first choice in the treatment of primary hypertension? A meta-analysis. Lancet. 2005;366(9496):1545-1553.

99. Gaddam K, Pimenta E, Thomas SJ, et al. Spironolactone reduces severity of obstructive sleep apnoea in patients with resistant hypertension: a preliminary report. J Hum Hypertens. 2010;24(8):532-537.

\section{Dovepress}

original research, clinical \& epidemiological studies, reviews \& evaluations, case reports and extended reports. The manuscript management system is completely online and includes a very quick and fair peerreview system, which is all easy to use. Visit http://www.dovepress.com/ testimonials.php to read real quotes from published authors. 